\title{
Assessment of the factorial and criterion validity of the General Charisma Inventory in a Spanish-speaking sample
}

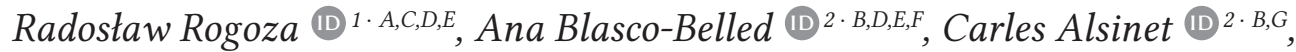 \\ Cristina Torrelles-Nadal (D) ${ }^{2 \cdot B}$, Norma fordana-Berenguer (D) ${ }^{2 \cdot B}$ \\ 1: Cardinal Stefan Wyszyński University, Warsaw, Poland \\ 2: University of Lleida, Lleida, Spain
}

BACKGROUND

Charisma can be understood as a personality trait that allows one to influence other people. Research on charisma has predominately focused on leadership, but it can also be successfully studied in the general population. The General Charisma Inventory (GCI) has not yet been analysed in different cultures. The current study represents the first attempt to examine and validate this instrument in a Spanish-speaking population.

\section{PARTICIPANTS AND PROCEDURE}

The $\mathrm{GCl}$ was administered in a series of three studies to a large adult community sample $(N 1=756, N 2=96$, $N 3=149$ ). A multigroup confirmatory factor analysis was conducted to verify the structure of the $\mathrm{GCl}$. Factorial and criterion validity was examined in the context of wellbeing and the Dark Triad traits. Measurement invariance across age and gender of the $\mathrm{GCl}$ in a Spanish-speaking sample was also analysed.

\section{RESULTS}

The results confirmed the hypothesised two-factorial structure and therefore the Spanish version of the $\mathrm{GCl}$ is a structurally valid and reliable measure, and its dimensions relate to different outcomes such as well-being and the Dark Triad.

\section{CONCLUSIONS}

The Spanish GCl could be used in general research on charisma and applied to a wide range of age groups within the Spanish-speaking context, providing economic screening for research and practice.

KEY WORDS

charisma; validity; structure; well-being; Dark Triad

CORRESPonding AUthor - Ana Blasco-Belled, Ph.D., University of Lleida, Avinguda de l'Estudi General 4, 25001 Lleida, Spain, e-mail: ana.blasco@udl.cat

authors' Contribution - A: Study design - B: Data collection - C: Statistical analysis - D: Data interpretation .

E: Manuscript preparation · F: Literature search · G: Funds collection

to Cite this ARticle - Rogoza, R., Blasco-Belled, A., Alsinet, C., Torrelles-Nadal, C., \& Jordana-Berenguer, N. (2021).

Assessment of the factorial and criterion validity of the General Charisma Inventory in a Spanish-speaking sample.

Current Issues in Personality Psychology, 9(1), 84-95.

RECEIVED 21.09.2020 • REVIEWED 29.10.2020 • ACCEPTED 28.12.2020 • PUBLISHED 26.01.2021 


\section{BACKGROUND}

The definition of charisma has evolved through the ages. Initially, Weber (1947) defined charisma as something supernatural, i.e., an extraordinary power, giving leaders salvationist qualities to deliver followers from great upheaval. House (1977), who introduced charisma into the organisational setting, emphasised that charisma is created from intensive emotional interactions with followers. More contemporary definitions refer to charisma as a constellation of personal characteristics allowing individuals to influence other people by affecting their feelings, opinions, and behaviours (Riggio, 2009). The processes of influencing other people are not the result of high authority or entitlement, but of voluntary cooperation (Hermalin, 1998). Thus, charisma is based not just on beliefs and symbolism but also on values and morals which, when combined, assist in the transmission of information (Antonakis et al., 2016).

When thinking about charisma, most people prototypically think about great leaders found in all walks of life, for example, Martin Luther King (religion), Steve Jobs (business), or Winston Churchill (politics). This is also reflected in empirical research, since charisma is primarily investigated within the context of leadership organisational settings (e.g., Antonakis, 2012). However, charisma could be observed not only in leaders, but also among close relatives or strangers (Friedman et al., 1980). This led Tshkay et al. (2018) to argue that charisma can be viewed as a personality trait that is present to a greater or lesser extent in all people.

Charisma is defined as a construct with two distinct faces: charismatic individuals are, on the one hand, able to influence, motivate, and attract other people to achieve common goals (House, 1977; Whitney et al., 1994); but on the other hand, they are able to maintain everyday social relations through warmth, trustworthiness and affability (Fiske et al., 2007; Keating, 2002). Charisma is thus hypothesised to consist of two dimensions: the first representing the ability to guide others, which is termed influence, and the second representing the ability to make others feel comfortable and at ease, which is termed affability (Tshkay et al., 2018).

\section{MEASURING CHARISMA}

The General Charisma Inventory (GCI), designed to measure influence and affability, was developed in a series of studies reported by Tshkay et al. (2018). An initial pool of items theoretically tapping the two dimensions of charisma that were generated through collecting public opinions comprised 408 indicators grouped into 100 categories. These 100 categories were further assessed in terms of the likelihood of being a good descriptor of charisma, which resulted in a pool of 40 items. In view of the results of exploratory factor analysis, which supported the existence of the underlying two-factorial structure, this pool was further reduced to 10 items. Next, based on the results of confirmatory factor analysis, the scale was trimmed to six items (three items on each scale) and yielded a good model fit. In four subsequent studies, Tshkay et al. (2018) claimed that the GCI is a valid and unique measure of charisma through the demonstration of a range of correlates of basic personality traits: emotionality, charismatic leadership and expressiveness, competence and warmth, and intelligence.

\section{OVERVIEW OF THE CURRENT STUDIES}

The GCI (Tshkay et al., 2018) seems to be a very promising tool to assess charisma, but to date its factor structure and validity have not been tested on a different culture. According to the International Test Commission Guidelines for Translating and Adapting Tests (2017), it is necessary to test the equivalence at different levels of complexity to ensure that the people in the groups being compared understand the construct being analysed in the same way. Previous work on the GCI did not analyse its equivalence across ages and genders although the joint analyses included adolescents and elderly people as well as males and females. It is important, therefore, to determine whether such comparisons are valid or not. Hence the aims of this research were to: (a) replicate the two-factor structure of the GCI in a Spanish-speaking population and to extend the literature through testing measurement invariance across (b) age groups and (c) gender. Moreover, in two follow-up studies we aimed to provide empirical evidence for validity through demonstrating differences in the concurrent validity of the various charisma dimensions. All the data, syntaxes, and supplementary materials necessary for replication of the results are available at https://osf.io/6x8zb/?view_ only=c9a82049fae24b3d91351af6fb2374c9.

\section{STUDY 1}

\section{PARTICIPANTS}

A total of $N=756$ adult participants from Spain, aged between 18 and 49 years $(M=33.77, S D=9.60$, $71.6 \%$ females) participated voluntarily in the study. The Spanish GCI was entered into a Google form and distributed by means of a snowball sampling methodology to collect data, by which research subjects facilitate the contact of third subjects to participate in the research, and so on (Vogt \& Johnson, 2011). This method of convenience sampling has been used 
to examine different populations and its application in quantitative studies has received empirical support (Cohen \& Arieli, 2011). In our case, we provided the link of the survey to four classes of psychology undergraduates and asked them to re-send the link to their acquaintances through the smartphone, with the only requisite of being $>18$ years old. They did not receive any compensation in exchange. Based on the original study of Tshkay et al. (2018), we attempted to find a similar size of around 750 participants. Accordingly, the sampling recruitment finished when we reached an approximate size. The participants had to read and accept an online informed consent form before completing the test. The final sample was divided into three age groups: $n=292$ participants younger than $30(M=23.33, S D=3.33,73.6 \%$ females $) ; n=203$ participants between 30 and $39(M=34.90, S D=2.89$, $70.4 \%$ females); and $n=261$ respondents who were 40 or older $(M=44.58, S D=2.79,70.1 \%$ females $)$. Based on previous research (e.g., Roberts et al., 2006), age thresholds were created arbitrarily to examine changes in personality traits. Gender distribution was equal across age groups $\left(\chi^{2}(2)=1.01, p=.604\right)$.

\section{MEASURES}

General Charisma Inventory (GCI). The GCI (Tshkay et al., 2018) is composed of six items designed to measure influence ( $\alpha=.68$; sample item: "Has a presence in a room") and affability ( $\alpha=.71$; sample item: "Makes people feel comfortable"); respondents answer using a five-point Likert-type scale from 1 (strongly disagree) to 5 (strongly agree). The validation followed a multistep process for translating and adapting tests (Muñiz et al., 2016). We (a) translated the items into Spanish, (b) consulted its linguistic and cultural suitability, (c) had the items back-translated into English by two independent translators, (d) reported the results to the original authors, and (e) discussed and added the authors' suggestions. First of all, the items were translated into first-person statements to make them more comprehensible in Spanish. During revision of the paper, we asked 8 Spanish native speakers to rate the suitability and comprehensiveness of two versions of the GCI using a ten-point scale: (a) a firstperson translation of the GCI and (b) a third-person translation of the GCI. The first-person statements received slightly higher ratings $(M=54.38, S D=7.21)$ than the third-person version $(M=52.25, S D=6.48)$, but this difference was not significant $(t(7)=0.67$, $p=.526$ ), suggesting that both versions are adequate.

\section{STATISTICAL ANALYSES}

The structure of the Spanish adaptation of the GCI across age and gender was verified using a multi- group confirmatory factor analysis, which was calculated using Mplus v. 7.2 (Muthén \& Muthén, 2014). The results were estimated using a robust maximum likelihood method approach due to likely violation of the multivariate normality assumption. In order to evaluate the model fit, we used CFI and RMSEA. An acceptable model fit is indicated when CFI $\geq .95$, TLI $\geq .95$, RMSEA $\leq .08$, left boundary of RMSEA confidence interval is $\leq .10$, and SRMR $\leq .10$ (SchermellehEngel et al., 2003). In multigroup analyses, it is possible to test for measurement invariance when three models are tested: configural (unconstrained), metric (with factor loadings constrained to be equal across groups), and scalar (with intercepts constrained to be equal across groups; Meredith, 1993). The data may be deemed as invariant when the difference in $\triangle \mathrm{CFI}$ does not exceed .010 and the difference in $\triangle$ RMSEA does not exceed .015 (Chen, 2007).

\section{RESULTS}

Item characteristics. Overall, participants scored higher on each item measuring affability (items 4-6) than on any item measuring influence (items 1-3), which is also reflected in a significant difference in their scores $(t(755)=-25.15, p<.001, d=0.92)$. The corrected item-total correlations (i.e., the correlation of a single item with the total score, which excludes this particular item) ranged from .43 to .61 for influence and from .47 to .60 for affability. The tested model was well fitted to the data $\left(\chi^{2}(8)=41.19\right.$, $p<.001, \mathrm{CFI}=.954, \mathrm{TLI}=.914, \mathrm{RMSEA}=.074,90 \%$ CI $[.053, .097]$, SRMR $=.046, \mathrm{BIC}=10929.01)$ and represented the GCI structure better than the one-factor model (which was itself poorly fitted: $\chi^{2}(9)=578.74$, $p<.001, \mathrm{CFI}=.217, \mathrm{TLI}=-.305, \mathrm{RMSEA}=.289,90 \%$ CI $[.270, .310]$, SRMR $=.135, \mathrm{BIC}=11316.34)$ as according to the BIC values and the difference in the $\chi^{2}$ between the models, the two-factor model yielded superior fit. The strength of the standardized factor loadings ranged between .53 and .87 , and the latent factor correlation was small $(\rho=.22, p<.001)$ and similar to the correlation between observed scores $(r=18, p<.001)$. A summary of descriptive statistics along with the reliability estimates, corrected itemtotal correlations, and standardized factor loadings is presented in Table 1.

Assessment of the GCI structure across age and gender. Results of the tested models (presented in Table 2) indicate that the two-factorial model is well fitted to the data, better than the one-factorial model, which showed poor adjustment as CFI ranged from $.379($ RMSEA $=.294)$ to $.719($ RMSEA $=.138)$ in the age groups and from .433 (RMSEA $=.274$ ) to .698 $(\mathrm{RMSEA}=.184)$ in the gender groups.

According to the values of $\triangle$ RMSEA, the twofactorial structure of the GCI may be deemed invari- 
Table 1

Item descriptive statistics, reliability estimates, corrected item-total correlation, and standardized factor loadings for total sample $(N=756)$

\begin{tabular}{|c|c|c|c|c|c|}
\hline Item (original form / Spanish adaptation) & M & $S D$ & $r_{\mathrm{IT}}$ & $\alpha$ & Factor loading \\
\hline 1I. Has a presence in a room / Tiene presencia & 3.06 & 0.88 & .43 & & .53 \\
\hline $\begin{array}{l}\text { 2l. Has the ability to influence people / Tiene la } \\
\text { habilidad de influir en los demás }\end{array}$ & 3.29 & 0.88 & .61 & & .87 \\
\hline $\begin{array}{l}\text { 3I. Knows how to lead a group / Sabe cómo liderar un } \\
\text { grupo }\end{array}$ & 3.41 & 0.98 & .46 & & .58 \\
\hline $\begin{array}{l}\text { 4A. Makes people feel comfortable / Hace que la gente } \\
\text { se sienta a gusto }\end{array}$ & 4.10 & 0.78 & .52 & & .68 \\
\hline 5A. Smiles at people often / A menudo sonríe a la gente & 4.34 & 0.85 & .60 & & .80 \\
\hline $\begin{array}{l}\text { 6A. Can get along with anyone / Puede llevarse bien } \\
\text { con cualquiera }\end{array}$ & 3.76 & 0.92 & .47 & & .56 \\
\hline Influence & 3.25 & 0.71 & & .68 & \\
\hline Affability & 4.07 & 0.68 & & .71 & \\
\hline
\end{tabular}

Note. $r_{\mathrm{IT}}$ - corrected item-total correlation; I - item measuring influence; A - item measuring affability.

Table 2

Summary of fit indices of the tested models and the tests for invariance across age and gender

\begin{tabular}{|c|c|c|c|c|c|c|c|c|c|}
\hline & $N$ & $\chi_{(\mathrm{df})}^{2}$ & $p$ & $\Delta \chi^{2}$ & $p$ & $\mathrm{CFI}$ & $\triangle \mathrm{CFI}$ & RMSEA & $\triangle \mathrm{RMSEA}$ \\
\hline \multicolumn{10}{|l|}{ Age } \\
\hline $18-29$ & 292 & $15.77_{(8)}$ & .048 & & & .975 & & .057 & \\
\hline $30-39$ & 203 & $13.70_{(8)}$ & .178 & & & .972 & & .046 & \\
\hline $40-49$ & 261 & $18.91_{(8)}$ & .014 & & & .966 & & .073 & \\
\hline \multicolumn{10}{|l|}{ Multigroup analysis } \\
\hline Configural & & $45.45_{(24)}$ & .001 & & & .971 & & .060 & \\
\hline Metric & & $56.86_{(32)}$ & .001 & $11.41_{(8)}$ & .167 & .966 & .005 & .056 & .004 \\
\hline Scalar & & $78.53_{(40)}$ & .001 & $21.67_{(8)}$ & .003 & .947 & .019 & .062 & .006 \\
\hline Partial scalar [6] & & $69.66_{(39)}$ & .001 & $13.08_{(7)}$ & .076 & .958 & .008 & .056 & .000 \\
\hline \multicolumn{10}{|l|}{ Gender } \\
\hline Men & 215 & $15.34_{(8)}$ & .053 & & & .964 & & .065 & \\
\hline Women & 541 & $42.72_{(8)}$ & .001 & & & .937 & & .090 & \\
\hline \multicolumn{10}{|l|}{ Multigroup analysis } \\
\hline Configural & & $55.00_{(16)}$ & .001 & & & .947 & & .080 & \\
\hline Metric & & $56.03_{(20)}$ & .001 & $1.03_{(4)}$ & .903 & .951 & .004 & .069 & .011 \\
\hline Scalar & & $76.16_{(24)}$ & .001 & $20.13_{(4)}$ & .001 & .929 & .022 & .076 & .007 \\
\hline Partial scalar [3] & & $63.60_{(23)}$ & .001 & $7.57_{(3)}$ & .059 & .945 & .006 & .068 & .001 \\
\hline
\end{tabular}


Table 3

Differences in latent mean scores of influence and affability across age groups and gender

\begin{tabular}{lccccc}
\hline & \multicolumn{3}{c}{ Age group } & \multicolumn{2}{c}{ Gender } \\
\cline { 2 - 6 } & $18-29$ & $30-39$ & $40-49$ & Women & Men \\
\hline Influence & .00 & $-.38^{* *}$ & $-.32^{* *}$ & .00 & $.19^{*}$ \\
Affability & .00 & -.15 & $-.26^{*}$ & .00 & -.17 \\
\hline
\end{tabular}

Note. ${ }^{*} p<.05,{ }^{* *} p<.01$.

ant across age and gender; however, the values of $\Delta$ CFI exceeded acceptable recommendations. Thus, following the procedure proposed by Gregorich (2006), in order to achieve partial scalar invariance, we freed the constraint of equal intercepts of a single item, which significantly improved the fit of the scalar model. Across age and gender, the GCI was found to have the same factor loadings, and with some minor exceptions, the same intercepts, which makes a comparison of latent mean scores meaningful. The differences in the latent scores of influence and affability across the compared groups are presented in Table 3.

In comparison to the 18-29 age group, we noted a significant and stable decrease in influence in other groups. Affability, however, decreased more slowly and was only significantly lower in the 40-49 age group. In regards to gender differences, men scored higher on influence, but no difference was found in affability.

\section{DISCUSSION}

Our results demonstrated that higher levels of charisma are more characteristic of younger people. The path of change, nonetheless, seems to be to some extent different for influence and affability. The drop in influence is more drastic among respondents in their thirties, and it negligibly decreases onwards, whereas the drop in affability begins rather slowly and continues to increase with age. These results contradict prior research on basic personality traits, because traits associated with charisma (i.e., social dominance and agreeableness) tended to increase with age (Roberts et al., 2006). Therefore, future studies (preferably longitudinal) are needed to address whether the dynamics of charisma differ with age or whether those differences are the result of studied generations.

In regards to gender differences, men scored significantly higher on influence than women, and no significant difference was found for affability (although women tended to score higher). These results are in accordance with existing studies reporting that men generally have a more agentic orientation, expressed by domination and competence, for example, whilst women generally have a more communal orientation expressed by nurturance and warmth (Wojciszke \& Szlendak, 2010). Our results may suggest that men and women have their own distinct ways of being perceived as charismatic.

\section{STUDY 2 - CHARISMA AND MENTAL HEALTH}

Ryan and Deci (2001) defined well-being as the optimal psychological functioning and experience. Two different aspects of well-being are represented in the literature: hedonic (i.e., subjective) well-being, which includes the more emotional aspects of wellbeing (i.e., life satisfaction, presence of positive mood and absence of negative mood; Diener, 2000); and eudaimonic (i.e., psychological) well-being, which involves the actualisation of human potential (Ryan \& Deci, 2001; Ryff, 1989). Studies have revealed that psychological well-being can be split further into two distinct components: psychological well-being and social well-being, with the latter representing the extent to which individuals thrive in their public and social life (Keyes, 2005). Because the influence dimension is more related to dominance, competence and the ability to achieve one's goals, we expect it to be related to the positive indicators of eudaimonic well-being (i.e., psychological and social well-being; Keyes, 2005). Affability, because of the association with emotionality and the ability to maintain positive social relationships, is hypothesised to be positively related to the indicators of well-being (Ryan \& Deci, 2001; Waterman, 2008).

\section{PARTICIPANTS}

The study was completed by $N=96$ adults $(71.9 \%$ females) from Spain aged between 20 and 72 $(M=47.58, S D=12.79)$. Data were collected by means of a snowball sampling method and the participants were asked to complete the measures in a Google 
form. The participants had to read and accept an online informed consent form prior to completing the test. There were no missing responses throughout the study.

\section{MEASURES}

The General Charisma Inventory (GCI; Tshkay et al., 2018) was used to measure general charisma. On average, the participants scored $M=3.52(S D=0.80)$ on influence and $M=4.25(S D=0.53)$ on affability. The reliability estimates in the current study were as follows: $\alpha=.80$ for influence and $\alpha=.66$ for affability. Both dimensions were positively correlated at $r=.36$ $(p<.001)$.

The Mental Health Continuum - Short Form (MHC-SF; Keyes, 1998; Spanish adaptation: Echeverria et al., 2017) was used to measure three components of well-being: emotional, social, and psychological. The scale is composed of 14 items which the respondents answer using a six-point Likert-type scale from 1 (never) to 6 (always). It has been validated across different cultures and demonstrates good psychometric properties (e.g., Karaś et al., 2014; Longo et al., 2017; Rogoza et al., 2018a). The reliability estimates in the current study were good: $\alpha=.81$ for emotional well-being, $\alpha=.83$ for social well-being, and $\alpha=.86$ for psychological well-being.

\section{STATISTICAL ANALYSES}

We began with evaluation of the GCI structure via the means of confirmatory factor analysis in accordance with recommendations reported in Study 1. Further, to evaluate the criterion validity, we ran correlational analyses supplemented by linear regression models in which charisma dimensions were entered as predictors of well-being.

\section{RESULTS}

The measurement model of the Spanish version of GCI was mostly well fitted to the data $\left(\chi^{2}(8)=13.34\right.$, $p=.101, \mathrm{CFI}=.960, \mathrm{TLI}=.925, \mathrm{RMSEA}=.083,90 \%$ CI $[.000, .159]$, SRMR $=.041)$ and the strength of the standardized factor loadings was adequate (range: .59-.89). The zero-order correlations between all studied variables are presented in Table 4.

Separate linear regression models with influence and affability as predictors of the three components of well-being were tested. The results are presented in Table 5.

All of the regression models were significant. Affability was a positive predictor of all of the well-being components, whereas influence did not predict emotional well-being ( $16 \%$ of variance was explained by the model), but was a positive predictor of social

Table 4

Zero-order correlations between all variables in Study 2

\begin{tabular}{lllll}
\hline & Influence & Affability & $\begin{array}{c}\text { Emotional } \\
\text { well-being }\end{array}$ & $\begin{array}{c}\text { Psychological } \\
\text { well-being }\end{array}$ \\
\hline Affability & $.36^{* *}$ & & \\
Emotional well-being & .13 & $.40^{* *}$ & \\
Psychological well-being & $.43^{* *}$ & $.50^{* *}$ & $.55^{* *}$ & $.59^{* *}$ \\
Social well-being & $.34^{* *}$ & $.46^{* *}$ & $.45^{* *}$ & \\
\hline Note. ${ }^{* *} p<.01$. & & &
\end{tabular}

\section{Table 5}

Dimensions of charisma predicting different components of well-being

\begin{tabular}{lccccccccc}
\hline & \multicolumn{3}{c}{ Influence } & \multicolumn{3}{c}{ Affability } & \multirow{2}{*}{$R^{2}$} & \multirow{2}{*}{$F(2,91)$} \\
\cline { 2 - 7 } & $B$ & $S E B$ & $\beta$ & $B$ & $S E B$ & $\beta$ & \\
\hline Emotional well-being & -.01 & .09 & -.02 & .51 & .13 & $.40^{* * *}$ & .16 & $4.45^{* *}$ \\
Social well-being & .21 & .11 & $.19^{*}$ & .67 & .16 & $.40^{* * *}$ & .26 & $8.10^{* *}$ \\
Psychological well-being & .24 & .08 & $.28^{* *}$ & .51 & .12 & $.39^{* * *}$ & .32 & $10.87^{* *}$ \\
\hline Note. Results were controlled for age and gender; ${ }^{*} p<.05,{ }^{* *} p<.01,{ }^{* * *} p<.001$. & & & &
\end{tabular}


well-being (24\% of variance was explained by the model) and psychological well-being (32\% of variance was explained by the model). Although the direction of the effects was the same for both dimensions of charisma, affability was generally a stronger predictor of well-being.

\section{DISCUSSION}

The results obtained in this study support the distinction of subjective and psychological well-being since affability emerged as the only predictor of emotional (i.e., subjective) well-being, whereas both dimensions of charisma predicted the social and psychological components of eudaimonic well-being. Affability, the ability to make other people feel good, seems to be more important in maintaining warm and stable interpersonal relationships, whereas influence seems to be a resource for initiating and developing them. To summarise, both dimensions of charisma account for variance of well-being independently and uniquely, which supports their concurrent criterion validity and thus makes it meaningful to consider both dimensions.

\section{STUDY 3 - CHARISMA AND THE DARK TRIAD PERSONALITY TRAITS}

Within the literature, three socially malevolent traits are frequently analysed together as the Dark Triad of personality (Paulhus \& Williams, 2002), i.e., narcissism, Machiavellianism, and psychopathy. Apart from sharing the common core of callousness (Paulhus, 2014), each of these traits has independent characteristics, such as exaggerated self-esteem in narcissism, impulse regulation ability in Machiavellianism, and thrill seeking in psychopathy (Rogoza \& Cieciuch, 2017, 2020). Dark Triad traits were investigated in workplace settings, predicting counterproductive work behaviour or vocational interests (Kowalski et al., 2017; O’Boyle et al., 2012). However, among the Dark Triad traits, charismatic tendencies were predominately attributed to narcissism (Young \& Pinsky, 2006). Previous research on narcissism provided mixed results, with some studies reporting positive relations to the indicators of charisma (such as conveying a charming facial expression; Back et al., 2010) and other studies reporting non-significant relations (Galvin et al., 2010). Rogoza and Fatfouta (2020), through the means of facet-level analyses, revealed that while the agentic facet of narcissism is related positively to influence (and to a lesser extent to affability), the antagonistic facet of narcissism is related negatively to affability. Antagonistic narcissism acts like a bridge linking agentic narcissism to Machiavellianism and psychopathy (Trahair et al., 2020) and it is phenotypically similar to these traits (Rogoza et al., 2019). Thus, one might expect that psychopathy and Machiavellianism should reveal a similar pattern of relations to charisma. Therefore, in the current study we expect that influence will be primarily and positively related to narcissism, which in the Dark Triad measures taps predominately on agentic aspects (Rogoza et al., 2018b). Moreover, we expect that affability will be negatively related to Machiavellianism and psychopathy.

\section{PARTICIPANTS}

The link to the study was sent to different local and student groups on a social networking site (Facebook). In total, $N=149$ participants (76.5\% female) completed the survey. Participants were mostly young adults aged between 18 and $50(M=23.91$, $S D=4.68)$. No missing responses were recorded.

\section{MEASURES}

The General Charisma Inventory (GCI; Tshkay et al., 2018) was again used as a measure of general charisma. In the current study we applied the third-person version of the measure. On average, respondents scored $M=3.24(S D=1.01)$ on influence and $M=3.71$ $(S D=0.95)$ on affability. The reliability estimates in the current study were good, i.e., $\alpha=.85$ for influence and $\alpha=.80$ for affability. Both dimensions were positively correlated at $r=.46(p<.001)$.

The Short Dark Triad (Jones \& Paulhus, 2014; Spanish adaptation: Pineda et al., 2020) was used to measure three socially malevolent traits referred as the Dark Triad of personality. The scale is composed of 27 items on which the respondents answer using a five-point Likert-type scale ranging from 1 (strongly disagree) to 5 (strongly agree). Although the scale is criticised for the high overlap between psychopathy and Machiavellianism (e.g., Persson et al., 2017; Rogoza \& Cieciuch, 2017), in empirical research it provides distinct and theoretically valid results (Jones \& Paulhus, 2017; Kowalski et al., 2018a, b). The reliability estimates in the current study were good: $\alpha=.78$ for Machiavellianism, and $\alpha=72$ for both narcissism and psychopathy.

\section{STATISTICAL ANALYSES}

Similar to Study 2, we began with evaluation of the GCI structure by means of confirmatory factor analysis. To assess whether the first- and third-person version are interpreted in similar vein, that is, whether the same items are loading the same latent factors, we compared their factorial equivalence. Factorial 
equivalence may be claimed when the approximate fit indices fall within the acceptable range, that is: $\mathrm{CFI} \geq .95$, TLI $\geq .95$, RMSEA $\leq .08$, left boundary of RMSEA confidence interval is $\leq .10$, and SRMR $\leq .10$ (Schermelleh-Engel et al., 2003). As in the previous study, to evaluate the criterion validity, we ran correlational analyses supplemented by linear regression models in which charisma dimensions were entered as predictors.

\section{RESULTS}

The analysed model was well fitted to the data $\left(\chi^{2}(8)=3.57, p=.894\right.$, CFI $=1.00$, TLI $=1.00$, RMSEA $=.000,90 \%$ CI $[.000, .043]$, SRMR $=.020)$ and the strength of the standardized factor loadings was adequate, ranging from .68 to .89 , confirming the two-dimensional structure of the GCI in the Spanishspeaking population.

The zero-order correlations between all studied variables are presented in Table 6.

As in the previous study, we tested three linear regression models of the relationship between dimensions of charisma and the Dark Triad traits. The results of the regression analyses are presented in Table 7.

All of the analysed regression models were significant. The first model explained almost half (42\%) of the variance in narcissism variance, and given that affability did not account for variance in narcissism, this presumably reflects the criterion validity of the influence dimension. Influence and affability explained less of the variance in psychopathy and Machiavellianism (19\% and $7 \%$ respectively) and they acted in opposite directions: influence was a positive predictor, whereas affability was a negative predictor, thus confirming our hypotheses.

\section{ASSESSMENT OF THE FACTORIAL EQUIVALENCE BETWEEN THE THIRD- AND FIRST-PERSON VERSION}

In the third study we used a different version of the measure, in which the items were presented in the third person. In order to test whether the respondents using the different versions of the measure understood charisma in the same way and whether, therefore, the two versions could be used interchangeably, we tested for factorial invariance across the data from Study 2 and Study 3. The model had a good fit to the data $\left(\chi^{2}(16)=15.70, p=.474\right.$, $\mathrm{CFI}=1.00, \mathrm{TLI}=1.00, \mathrm{RMSEA}=.00,90 \% \mathrm{CI}[.00$, $.08]$, SRMR $=.030$ ), supporting factorial equivalence of the two versions, indicating that both of them could be used in research on Spanish-speaking populations.

Table 6

Zero-order correlations between all variables in Study 3

\begin{tabular}{lcccc}
\hline & Influence & Affability & Narcissism & Machiavellianism \\
\hline Affability & $.46^{* *}$ & & & \\
Narcissism & $.65^{* *}$ & $.30^{* *}$ & & \\
Machiavellianism & .12 & -.15 & $.27^{* *}$ & $.30^{* *}$ \\
Psychopathy & $.18^{*}$ & $-.27^{* *}$ & $.67^{* *}$ \\
\hline
\end{tabular}

Note. ${ }^{*} p<.05,{ }^{* *} p<.01$.

Table 7

Dimensions of charisma predicting the Dark Triad traits

\begin{tabular}{lccccccccc}
\hline & \multicolumn{3}{c}{ Influence } & \multicolumn{3}{c}{ Affability } & \multirow{2}{*}{$R^{2}$} & \multirow{2}{*}{$F(2,93)$} \\
\cline { 2 - 7 } & $B$ & $S E B$ & $\beta$ & $B$ & $S E B$ & $\beta$ & \\
\hline Narcissism & .42 & .05 & $.64^{* *}$ & .01 & .05 & .01 & .42 & $51.93^{* *}$ \\
Machiavellianism & .18 & .07 & $.24^{* *}$ & -.21 & .07 & $-.26^{* *}$ & .07 & $5.26^{* *}$ \\
Psychopathy & .26 & .06 & $.39^{* *}$ & -.31 & .06 & $-.44^{* *}$ & .19 & $16.96^{* *}$ \\
\hline Note. ${ }^{* *} p<.01$. & & & & & & & &
\end{tabular}




\section{DISCUSSION}

Narcissism was most strongly associated with charisma, which is not surprising since narcissists are described as possessing an immediately perceptible charm and charisma (Young \& Pinsky, 2006). While we replicated these results in correlational analyses, when we controlled for the shared variance of the influence and affability, narcissism was related only to the latter, which may reflect the difference between narcissism and charisma. Both are superficially associated with boldness, visionary quality and self-confidence, but while extended contact leads to this impression of narcissists wearing off due to their arrogance, lack of concern for others and sense of entitlement (Fatfouta, 2018; Ong et al., 2016), it may be more persistent in the case of charismatic individuals due to their affability. Hence, although there are similarities between narcissism and influence, affability seems to differentiate them.

The lack of relationship between influence and Machiavellianism might be surprising at first glance, but it is theoretically plausible. The influence dimension of charisma reflects agentic attitudes (Tshkay et al., 2018). However, among the Dark Triad traits, only narcissism seems to be related to the agencyrelated traits such as intelligence. While this is incongruent with their actual abilities (Zajenkowski \& Czarna, 2015; Zajenkowski et al., 2020), only narcissists are perceived by others as more agentic (Rauthmann \& Kolar, 2013), which results in agencyrelated outcomes such as being nominated as a leader (Rogoza et al., 2020). Furthermore, narcissism in the context of the Dark Triad predominately taps its agentic facet, while antagonistic features are assessed to a limited extent (Rogoza et al., 2019). These antagonistic features have much more in common with Machiavellianism and psychopathy (Trahair et al., 2020); thus, it is not surprising to see a null relation (Rogoza \& Fatfouta, 2020). The lack of relationship between Machiavellianism and affability is against our expectations; however, existing research suggests that Machiavellianism is less specific in its operationalisation than psychopathy (Rogoza et al., 2019). Therefore, seeing the same pattern of relationship but of lesser magnitude is understandable.

\section{GENERAL DISCUSSION}

The current study was the first attempt to test the psychometric properties of the GCI (Tshkay et al., 2018) in a different culture. The obtained results of the assessment of the factorial validity corroborate the findings of Tshkay et al. (2018) supporting the assertion that charisma is composed of influence and affability; thus, the GCI may be successfully used in a Spanish-speaking population. Our findings demon- strate that the structure of the GCI is partially invariant across age and gender and, moreover, we supported the criterion validity through demonstrating the differential relationships of influence and affability with well-being and the Dark Triad traits.

In the original study, mean influence scores ranged between 3.37 and 3.45 and affability scores were slightly higher, at between 3.72 and 3.89 . In the series of studies reported here, mean affability scores were once again higher than influence scores, although those obtained in Study 3 were closer to the estimates reported by Tshkay et al. (2018). Similarly, Tshkay et al. (2018) reported reliability estimates ranging between .77 and .85 for influence and between .75 and .82 for affability, while only those reported in our Study 3 fell within this range. Moreover, correlations between influence and affability reported in the original study ranged from .50 to .52 , whereas in Study 1 it was lower, and in Study 3 it was similar in strength. The difference between Study 3 and Studies 1 and 2 was in the form of the questionnaire - in the first two studies the items were presented in the first person, whereas in the last study they were presented in the third person. Although we have provided evidence that these versions have the same factor structure and are similarly comprehensible to native speakers, on the basis of comparability of psychometric properties (i.e., mean values, reliability estimates, correlation strength), the thirdperson version seems to be preferred for use in future studies as it more closely aligns with the results reported by Tshkay et al. (2018).

\section{LIMITATIONS}

This research has several limitations, which should be taken into account when interpreting the results. First, the sampling procedure was probabilistic and the sample was not representative of the Spanish population. More specifically, the sample of Study 2 was small and imbalanced in terms of gender proportion. This research provides a starting point for further empirical research with the Spanish version of the GCI. Second, demographic information about the sample is limited to age (young populations) and gender (higher female prevalence); thus, generalising the results to the whole population should be done with great caution. Moreover, in the first two studies we used a first-person version of the questionnaire, whereas in the original study statements were presented in the third person. Although the aim of the first-person version was to make the Spanish version easier to understand, the empirical results tend to suggest that the original, third-person Spanish version was better. Therefore, we recommend caution when generalising the results reported here to the Spanish-speaking population. Finally, this research 
relies entirely on self-report data and so experimental and longitudinal studies are required to provide further support for the validity of the charisma dimensions.

\section{CONCLUSIONS}

In summary, the current study was the first to analyse the dimensionality and validity of the GCI in a Spanish-speaking sample. As there are more than 500 million native Spanish speakers in the world (Fernández Vítores, 2017), providing information on the psychometric properties of the different measures is an important task. On the basis of the results presented within this paper, the Spanish version of the GCI (Tshkay et al., 2018) may be deemed a valid tool that measures two dimensions of charisma. The findings from these studies have implications for research - for example, we found that influence and narcissism were strongly related, while affability was unrelated to narcissism. Future studies could investigate the degree of similarity in the underlying behavioural dynamics of narcissism and charisma. The findings from this research could also be put into practical use - e.g., the Spanish version of the GCI could be used to assess charisma in organisational settings. Owing to the differential relationships of the charisma dimensions with the Dark Triad traits, which have been related to counterproductive work behaviour (O’Boyle et al., 2012), this kind of assessment might help in the selection of individuals who are likely to display desirable workplace behaviours in the future.

\section{REFERENCES}

Antonakis, J. (2012). Transformational and charismatic leadership. In D. V. Day \& J. Antonakis (Eds.), The nature of leadership (2nd edition, pp. 256-288). Sage.

Antonakis, J., Bastardoz, N., Jacquart, P., \& Shamir, B. (2016). Charisma: an ill-defined and ill-measured gift. Annual Review of Organizational Psychology and Organizational Behavior, 3, 293-319. https:// doi.org/10.1146/annurev-orgpsych-041015-062305

Back, M. D., Schmukle, S. C., \& Egloff, B. (2010). Why are narcissists so charming at the first sight? Decoding the narcissism-popularity link at zero acquaintance. Journal of Personality and Social Psychology, 98, 132-145. https://doi.org/10.1037/a0016338

Chen, F. F. (2007). Sensitivity of goodness of fit indexes to lack of measurement invariance. Structural Equation Modeling, 14, 464-504. https://doi. org/10.1080/10705510701301834

Cohen, N., \& Arieli, T. (2011). Field research in conflict environments: Methodological challenges and snowball sampling. Journal of Peace Research, 48, 423-435. https://doi.org/10.1177/0022343311405698

Diener, E. D. (2000). Subjective well-being: The science of happiness and a proposal for a national index. American Psychologist, 55, 34-43. https://doi. org/10.1037/0003-066X.55.1.34

Echeverria, G., Torres, M., Pedrals, N., Padilla, O., Rigorri, A., \& Bitran, M. (2017). Validation of a Spanish version of the Mental Health Continuum-Short Form questionnaire. Psicothema, 29, 96-102. https://doi.org/10.7334/psicothema2016.3

Fatfouta, R. (2018). Facets of narcissism and leadership: A tale of Dr. Jekyll and Mr. Hyde? Human Resource Management Review, 29, 100669. https:// doi.org/10.1016/j.hrmr.2018.10.002

Fernández Vítores, D. (2017). El Español: Una lengua viva [Spanish: a living language]. Instituto Cervantes. Retrieved from: https://cvc.cervantes.es/ lengua/espanol_lengua_viva/pdf/espanol_lengua_viva_2017.pdf

Fiske, S. T., Cuddy, A. J., \& Glick, P. (2007). Universal dimensions of social cognition: Warmth and competence. Trends in Cognitive Sciences, 11, 77-83. https://doi.org/10.1016/j.tics.2006.11.005

Friedman, H. S., Prince, L. M., Riggio, R. E., \& DiMatteo, M. R. (1980). Understanding and assessing nonverbal expressiveness: The Affective Communication Test. Journal of Personality and Social Psychology, 39, 333-351. https://doi.org/10.1037/00223514.39.2.333

Galvin, B. M., Waldman, D. A., \& Balthazard, P. (2010). Visionary communication qualities as mediators of the relationship between narcissism and attributions of leader charisma. Personnel Psychology, 63, 509-537. https://doi.org/10.1111/ j.1744-6570.2010.01179.x

Gregorich, S. E. (2006). Do self-report instruments allow meaningful comparisons across diverse population groups? Testing measurement invariance using the confirmatory factor analysis framework. Medical Care, 44, 78-94. https://doi.org/10.1097/01. mlr.0000245454.12228.8f

Hermalin, B. E. (1998). Toward an economic theory of leadership: Leading by example. The American Economic Review, 88, 1188-1206. https://doi.org/ $10.2139 /$ ssrn. 15570

House, R. J. (1977). A 1976 theory of charismatic leadership. In J. G. Hunt \& L. L. Larson (Eds.), Leadership: The cutting edge (pp. 189-207). Southern IIlinois University Press.

International Test Commission (2017). ITC Guidelines for translating and adapting tests (2nd edition). ITC

Jones, D. N., \& Paulhus, D. L. (2014). Introducing the Short Dark Triad (SD3): a brief-measure of dark personality traits. Assessment, 21, 28-41. https:// doi.org/10.1177/1073191113514105

Jones, D. N., \& Paulhus, D. L. (2017). Duplicity among the Dark Triad: Three faces of deceit. Journal of 
Personality and Social Psychology, 113, 329-342. https://doi.org/10.1037/pspp0000139

Karaś, D., Cieciuch, J., \& Keyes, C. L. M. (2014). The Polish adaptation of the Mental Health Continuum-Short Form (MHC-SF). Personality and Individual Differences, 69, 104-109. https://doi. org/10.1016/j.paid.2014.05.011

Keating, C. F. (2002). Charismatic faces: Social status cues put face appeal in context. In G. Rhodes \& L. A. Zebrowitz (Eds.), Facial attractiveness (pp.153-192). Ablex.

Keyes, C. L. M. (1998). Social well-being. Social Psychology Quarterly, 61, 121-140. https://doi.org/10. $2307 / 2787065$

Keyes, C. L. M. (2005). Mental illness and/or mental health? Investigating axioms of the complete state model of health. Journal of Consulting and Clinical Psychology, 73, 539-548. https://doi.org/ 10.1037/0022-006X.73.3.539

Kowalski, C. M., Kwiatkowska, K., Kwiatkowska, M. M., Ponikiewska, K., Rogoza, R. \& Schermer, J. A. (2018a). The Dark Triad traits and intelligence: Machiavellians are bright, and narcissists and psychopaths are ordinary. Personality and Individual Differences, 135, 1-6. https://doi. org/10.1016/j.paid.2018.06.049

Kowalski, C. M., Rogoza, R., Vernon, P. A., \& Schermer, J. A. (2018b). The Dark Triad and the self-presentation variables of socially desirable responding and self-monitoring. Personality and Individual Differences, 120, 234-237. https://doi.org/10.1016/j. paid.2017.09.007

Kowalski, C. M., Vernon, P. A., \& Schermer, J. A. (2017). Vocational interests and dark personality: Are there dark career choices? Personality and Individual Differences, 103, 43-47. https://doi.org/10.1016/j. paid.2016.07.029

Longo, Y., Jovanović, V., Sampaio de Carvalho, J., \& Karaś, D. (2017). The general factor of wellbeing: Multinational evidence using bifactor ESEM on the Mental Health Continuum-Short Form. Assessment, 27, 596-606. https://doi.org/10. 1177/1073191117748394

Meredith, W. (1993). Measurement invariance, factor analysis and factorial invariance. Psychometrika, 58, 525-543. https://doi.org/10.1007/BF02294825

Muñiz, J., Elosua, P., Padilla, J. L., \& Hambleton, R. K. (2016). Test adaptation standards for cross-lingual assessment. In C. S. Wells \& M. Faulkner-Bond (Eds.), Educational measurement. From foundations to future (pp. 291-304). The Guilford Press.

Muthén, L. K., \& Muthén, B. O. (2014). Mplus user's guide (7th ed.). Muthén \& Muthén.

O’Boyle, E. H., Forsyth, D. R., Banks, G. C., \& McDaniels, M. A. (2012). A meta-analysis of the Dark Triad and work behavior: a social exchange perspective. Journal of Applied Psychology, 97, 557-579. https://doi.org/10.1037/a0025679
Ong, C. W., Roberts, R., Arthur, C. A., Woodman, T., \& Akehurst, S. (2016). The leadership is sinking: a temporal investigation of narcissistic leadership. Journal of Personality, 84, 237-247. https:// doi.org/10.1111/jopy. 12155

Paulhus, D. L. (2014). Toward a taxonomy of dark personalities. Current Directions in Psychological Science, 23, 421-426. https://doi.org/10.1177/0963721 414547737

Paulhus, D. L., \& Williams, K. M. (2002). The Dark Triad of personality: Narcissism, Machiavellianism, and psychopathy. Journal of Research in Personality, 36, 556-563. https://doi.org/10.1016/ S0092-6566(02)00505-6

Persson, B. N., Kajonius, P. J., \& Garcia, D. (2017). Revisiting the structure of the Short Dark Triad. Assessment, 26, 3-16. https://doi.org/10.1177/1073191117701192

Pineda, D., Sandin, B., \& Muris, P. (2020). Psychometric properties of the Spanish version of two Dark Triad scales: The Dirty Dozen and the Short Dark Triad. Current Psychology, 39, 1873-1881. https:// doi.org/10.1007/s12144-018-9888-5

Rauthmann, J. F., \& Kolar, G. P. (2013). The perceived attractiveness and traits of the Dark Triad: Narcissists are perceived as hot, Machiavellians and psychopaths not. Personality and Individual Differences, 54, 582-586. https://doi.org/10.1016/j.paid.2012.11.005

Riggio, R. E. (2009). Charisma. In S. J. Lopez (Ed.), Encyclopedia of positive psychology (pp. 141-144). Blackwell.

Roberts, B. W., Walton, K. E., \& Viechtbuer, W. (2006). Patterns of mean-level change in personality traits across the life course: a meta-analysis of longitudinal studies. Psychological Bulletin, 132, 1-25. https://doi.org/10.1037/0033-2909.132.1.1

Rogoza, R., \& Cieciuch, J. (2017). Structural investigation of the Short Dark Triad questionnaire in Polish population. Current Psychology, 38, 756-763. https://doi.org/10.1007/s12144-017-9653-1

Rogoza, R., \& Cieciuch, J. (2020). Dark Triad traits and their structure: an empirical approach. Current Psychology, 39, 1287-1302. https://doi.org/10.1007/ s12144-018-9834-6

Rogoza, R., Danieluk, B., Kowalski, C. M., Kwiatkowska, K., \& Kwiatkowska, M. M. (2020). Making and maintaining relationships through the prism of the Dark Triad traits: a longitudinal social network study. Journal of Personality. https://doi. org/10.1111/jopy. 12585

Rogoza, R., \& Fatfouta, R. (2020). Decoding the narcissism-charisma link: a facet approach. Personality and Individual Differences, 156, 109774. https:// doi.org/10.1016/j.paid.2019.109774

Rogoza, R., Kowalski, C. M., \& Schermer, J. A. (2019). Dark Triad traits within the framework of the Circumplex of Personality Metatraits Model. Journal of Individual Differences, 40, 168-176. https://doi. org/10.1027/1614-0001/a000289 
Rogoza, R., Truong, T. K. H., Różycka-Tran, J., Piotrowski, J., \& Żemojtel-Piotrowska, M. (2018a). Psychometric properties of the MHC-SF: an integration of the existing measurement approaches. Journal of Clinical Psychology, 74, 1742-1758. https://doi. org/10.1102/jclp.22626

Rogoza, R., Żemojtel-Piotrowska, M., \& Campbel, W. K. (2018b). Measurement of narcissism: From classical applications to modern approaches. Studia Psychologica, 1, 27-48. https://doi.org/10.21697/sp. 2018.18.1.02

Ryan, R. M., \& Deci, E. L. (2001). On happiness and human potentials: a review of research on hedonic and eudaimonic well-being. Annual Review of Psychology, 52, 141-166. https://doi.org/10.1146/ annurev.psych.52.1.141

Ryff, C. D. (1989). Happiness is everything, or is it? Explorations on the meaning of psychological well-being. Journal of Personality and Social Psychology, 57, 1069-1081. https://doi.org/10.1037/ 0022-3514.57.6.1069

Schermelleh-Engel, K., Moosbrugger, H., \& Müller, H. (2003). Evaluating the fit of structural equation models: Tests of significance and descriptive goodness-of-fit measures. Methods of Psychological Research Online, 8, 23-74.

Trahair, C., Baran, L., Flakus, M., Kowalski, C. M., \& Rogoza, R. (2020). The structure of the Dark Triad traits: a network analysis. Personality and Individual Differences, 167, 110265. https://doi. org/10.1016/j.paid.2020.110265

Tskhay, K. O., Zhu, R., Zou, C., \& Rule, N. O. (2018). Charisma in everyday life: Conceptualization and validation of the General Charisma Inventory. Journal of Personality and Social Psychology, 114, 131-152. https://doi.org/10.1037/pspp0000159

Vogt, W. P., \& Johnson, B. (2011). Dictionary of statistics and methodology: a nontechnical guide for the social sciences. Sage.

Waterman, A. S. (2008). Reconsidering happiness: a eudaimonist's perspective. The Journal of Positive Psychology, 3, 234-252. https://doi.org/10.1080/ 17439760802303002

Weber, M. (1947). The theory of social and economic organization. The Free Press.

Whitney, K., Sagrestano, L. M., \& Maslach, C. (1994). Establishing the social impact of individuation. Journal of Personality and Social Psychology, 66, 11401153. https://doi.org/10.1037/0022-3514.66.6.1140

Wojciszke, B., \& Szlendak, M. (2010). Scales measuring agency and communion. Psychologia Spoteczna, 5, 57-70.

Young, S. M., \& Pinsky, D. (2006). Narcissism and celebrity. Journal of Research in Personality, 40, 463-471. https://doi.org/10.1016/j.jrp.2006.05.005

Zajenkowski, M., \& Czarna, A. Z. (2015). What makes narcissists unhappy? Subjectively assessed intelligence moderates the relationship between nar- cissism and psychological well-being. Personality and Individual Differences, 77, 50-54. https://doi. org/10.1016/j.paid.2014.12.045

Zajenkowski, M., Czarna, A. Z., Szymaniak, K., \& Dufner, M. (2020). What do highly narcissistic people think and feel about (their) intelligence? Journal of Personality, 88, 703-718. https://doi. org/10.1111/jopy. 12520 